\title{
Preoperative PFTs: The answer is blowing in the wind
}

\author{
Paul Kurlansky, MD
}

\author{
From the Department of Surgery, Columbia University, New York, NY \\ Disclosures: Author has nothing to disclose with regard to commercial support. \\ Received for publication Dec 10, 2015; accepted for publication Dec 11, 2015; available ahead of print Jan 22, \\ 2016. \\ Address for reprints: Paul Kurlansky, MD, Department of Surgery, Columbia University, Black Building 210, 650 \\ W 168th St, New York, NY 10032 (E-mail: pk2245@cumc.columbia.edu). \\ J Thorac Cardiovasc Surg 2016;151:918-9 \\ $0022-5223 / \$ 36.00$ \\ Copyright $(2) 2016$ by The American Association for Thoracic Surgery \\ http://dx.doi.org/10.1016/j.jtcvs.2015.12.024
}

As a member of the Quality Management Task Force of the Society of Thoracic Surgeons (STS), I studied with interest the work of Ivanov and colleagues in this issue of the Jour$n a l,{ }^{1}$ which asks the important question of whether pulmonary function tests (PFTs) (Figure 1) improve risk stratification before cardiothoracic surgery. This question has both practical and theoretical implications. Although not apparent in all published studies, 2,3 preexisting pulmonary disease is generally associated with both increased operative risk $^{4,5}$ and diminished long-term survival in patients who undergo cardiac surgery. ${ }^{6-8}$ In fact, there is a strong correlation between reduced lung function and cardiovascular disease, independent of age, smoking, and other obvious confounders, that awaits mechanistic explanation. ${ }^{9,10}$ Therefore, accurate preoperative evaluation of pulmonary function takes on both clinical and physiological significance.

It is this context that the question of how to best evaluate preoperative pulmonary function becomes compelling. Unfortunately, the study by Ivanov and colleagues appears to fall quite short of this challenge. Compared with the hundreds of cardiac surgical centers and hundreds of thousands of patients used to derive the 2008 Society of Thoracic Surgeons (STS) risk models, this study was derived from a single institution over 10 years with only 1618 patients available, and correspondingly very few endpoints on which to base the analysis, which almost certainly was underpowered. The data appear to have been collected initially to satisfy New York State cardiac surgery reporting requirements, then modified to satisfy STS definitions. The endpoint definition for prolonged ventilation in the current study is quite different than that for which the STS risk model was developed (72 hours vs 24 hours), as is the mortality endpoint (30 days or inhospital for STS vs apparently only 30 days for the current study). These factors likely account for the relatively poor discrimination of the STS risk models in the current study population compared with that in the considerably broader STS population. The specific definition of chronic lung disease applied to the patients in the study is not clear, and that attributed to the STS in Table 1 is incomplete,

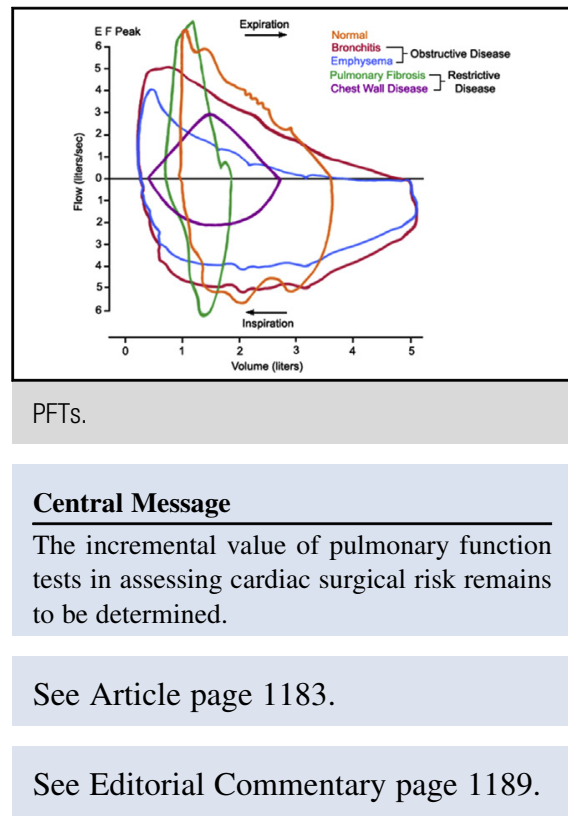

lacking PFTs, which are integral to that definition. PFTs were available for only approximately one-half of the patients, and in the vast majority of these patients were limited to bedside spirometry, which is not accepted in the STS criteria. Finally, improvements in area under the curve values are generally considered an inadequate major criterion for determining the value of added components to a risk model. ${ }^{11}$

The shortcomings of this study provide no assurance that the question raised in the opening sentence has been adequately addressed. Indeed, neither the EuroSCORE I or II $^{12-14}$ nor the New York State risk calculators for coronary or valvular surgery ${ }^{15,16}$ —all of which address operative mortality only-include PFTs in their risk models. Nonetheless, the ability of PFTs to reclassify chronic obstructive pulmonary disease (COPD) status in a substantial number of patients before cardiac surgery, through both identification of unrecognized disease and demonstration of the absence of airway obstruction in patients previously labeled as having COPD, is of concern, especially when one considers that it was this degree of PFT-defined airway obstruction that correlated with mortality. ${ }^{17}$ Is it possible that clearer, more universally accepted and carefully considered criteria for the diagnosis would eliminate the need for PFT testing in the evaluation of operative risk? Is spirometry sufficient, or should the evidence that diffusing capacity has an independent and incremental impact on postoperative mortality compel us to 


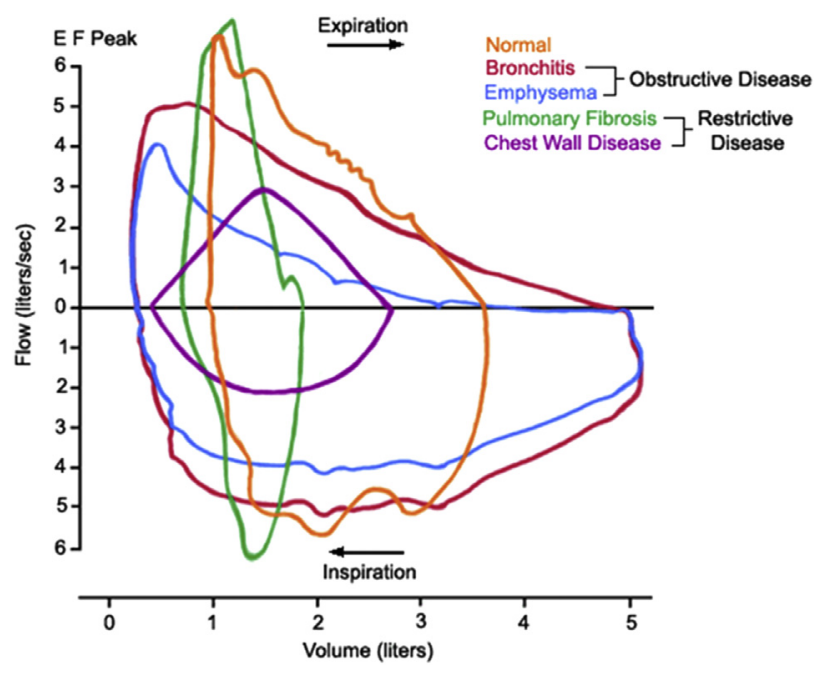

FIGURE 1. Pulmonary function tests.

measure that as well $?^{17}$ Are there mechanisms involved that transcend the intuitive association with pulmonary complications? Ivanov and colleagues are to be thanked for raising an important question; however, the answer awaits a more definitive and convincing evaluation.

\section{References}

1. Ivanov A, Yossef J, Tailon J, Worku BM, Gulkarov I, Tortolani AJ, et al. Do pulmonary function tests improve risk stratification before cardiothoracic surgery? $J$ Thorac Cardiovasc Surg. 2016;151:1183-9.e3.

2. Michalopoulos A, Geroulanos S, Papadimitriou L, Papadakis E, Triantafillou K, Papadopoulos K, et al. Mild or moderate chronic obstructive pulmonary disease risk in elective coronary artery bypass grafting surgery. World J Surg. 2001;25: 1507-11.

3. Canver CC, Nichols RD, Kroncke GM. Influence of age-specific lung function on survival after coronary bypass. Ann Thorac Surg. 1998;66:144-7.
4. Clough RA, Leavitt BJ, Morton JR, Plume SK, Hernandez F, Nugent W, et al. The effect of comorbid illness on mortality outcomes in cardiac surgery. Arch Surg. 2002;137:428-33.

5. Rosenthal GE, Vaughan Sarrazin M, Hannan EL. In-hospital mortality following coronary artery bypass graft surgery in Veterans Health Administration and private sector hospitals. Med Care. 2003;41:522-35.

6. Leavitt BJ, Ross CS, Spence B, Surgenor SD, Olmstead EM, Clough RA, et al; for the Northern New England Cardiovascular Disease Study Group. Long-term survival of patients with chronic obstructive pulmonary disease undergoing coronary artery bypass surgery. Circulation. 2006;114(Suppl I): I430-4.

7. Angouras DC, Anagnostopoulos CE, Chamogeorgakis TP, Rokkas CK, Swistel DG, Connery CP, et al. Postoperative and long-term outcome of patients with chronic obstructive pulmonary disease undergoing coronary artery bypass grafting. Ann Thorac Surg. 2010;89:1112-8.

8. Wu C, Camacho FT, Wechsler AS, Lahey S, Culliford AT, Jordan D, et al. Risk score for predicting long-term mortality after coronary artery bypass graft surgery. Circulation. 2012;125:2423-30.

9. Sin DD, Wu LL, Man SFP. The relationship between reduced lung function and cardiovascular mortality: a population-based study and systematic review of the literature. Chest. 2005; 127:1952-9.

10. Bolton CE, Cockcroft JR. Lung function and cardiovascular risk: a stiff challenge? Am J Hypertens. 2010;23:584.

11. Pencina MJ, D’Agostino RB, Pencina KM, Janssens AC, Greenland P. Interpreting incremental value of markers added to risk prediction models. Am J Epidemiol. 2012;176:473-81.

12. Roques F, Nashef SA, Michel P, Gauducheau E, de Vincentiis C, Baudet E, et al Risk factors and outcome in European cardiac surgery: analysis of the EuroSCORE multinational database of 19030 patients. Eur J Cardiothorac Surg. 1999;15:816-22.

13. Roques F, Michel P, Goldstone AR, Nashef SA. The logistic EuroSCORE. Eur Heart J. 2003;24:882-3.

14. Nashef SA, Roques F, Sharples LD, Nilsson J, Smith C, Goldstone AR, et al EuroSCORE II. Eur J Cardiothorac Surg. 2012;41:734-44.

15. Hannan EL, Farrell LS, Wechsler A, Jordan D, Lahey SJ, Culliford AT, et al. The New York risk score for in-hospital and 30-day mortality for coronary artery bypass graft surgery. Ann Thorac Surg. 2013;95:46-52.

16. Hannan EL, Racz M, Culliford AT, Lahey SJ, Wechsler A, Jordan D, et al. Risk score for predicting in-hospital/30-day mortality for patients undergoing valve and valve/coronary artery bypass graft surgery. Ann Thorac Surg. 2013;95: 1282-90.

17. Adabag AS, Wassif HS, Rice K, Mithani S, Johnson D, Bonawitz-Conlin J, et al Preoperative pulmonary function and mortality after cardiac surgery. Am Heart J. 2010;159:691-7. 